\title{
LISTA ATUALIZADA DAS ORCHIDACEAE DO DISTRITO FEDERAL
}

\author{
João Aguiar Nogueira Batista ${ }^{1}$ \\ Luciano de Bem Bianchetti ${ }^{1}$
}

\section{Recebido em 18/06/2001. Aceito em 17/06/2002}

\begin{abstract}
RESUMO - (Lista atualizada das Orchidaceae do Distrito Federal). É apresentada a relação atualizada de Orchidaceae para o Distrito Federal (DF), a unidade da federação onde se situa a capital brasileira, localizada no centro do país. São reconhecidos 72 gêneros e 254 táxons (246 espécies e oito táxons subespecíficos), dos quais 17 (6,7\%) são conhecidos apenas localmente. Os gêneros mais significativos no DF são Habenaria (74 espécies e três táxons subespecíficos), Cyrtopodium (17 espécies), Cleistes (13 espécies) e a subtribo Spiranthinae (11 gêneros com 34 espécies e dois táxons subespecíficos). Gêneros como Epidendrum (oito espécies), Pleurothallis (sete espécies), Oncidium (seis espécies) e Maxillaria (três espécies) são abundantes na Mata Atlântica no sudeste brasileiro, mas pouco representados na região. Cerca de $73 \%$ das Orchidaceae do DF apresentam hábito terrestre, o que contrasta marcadamente com a Mata Atlântica e a região Amazônica, onde predominam espécies epifíticas. Dentro do Cerrado, o DF representa o local mais bem amostrado e com o maior número de espécies conhecidas, compreendendo cerca de 51\% das orquídeas listadas para todo o bioma. Esta relação tem como objetivo subsidiar a monografia desta família para a flora do Distrito Federal.
\end{abstract}

Palavras-chave - Orchidaceae, orquídeas, florística, Cerrado, Distrito Federal, Brasil

\begin{abstract}
Checklist of the Orchidaceae from the Distrito Federal). The survey of the Orchidaceae from the Distrito Federal (DF), the administrative region of the Brazilian capital located at the center of the country, is presented. Currently, 72 genera and 254 taxa (246 species and eight subspecific taxa) are recognized, 17 (6.7\%) of which are known only locally. The most representative genera are Habenaria (74 species and three subspecific taxa), Cyrtopodium (17 species), Cleistes (13 species) and subtribe Spiranthinae (11 genera, 34 species and two subspecific taxa). Genera like Epidendrum (eight species), Pleurothallis (seven species), Oncidium (six species) and Maxillaria (three species) are abundant in the Atlantic rain forest in southeastern Brazil, but poorly represented in the region. About $73 \%$ of the Orchidaceae from the DF are terrestrials, in contrast with the Atlantic forest and Amazon region, were the epiphytes predominate. The Distrito Federal is the better-sampled region and has the higher number of Orchidaceae in the cerrado region, comprising about $51 \%$ of the orchids known from this biome. The aim of this survey is to subsidize the monograph of the family for the forthcoming "Flora of the Distrito Federal".
\end{abstract}

Key words - Orchidaceae, orchids, floristic survey, cerrado vegetation, Federal District, Brazil

Embrapa Recursos Genéticos e Biotecnologia, C. Postal 02372, CEP 70770-901, Brasília, DF, Brasil (janb@ cenargen.embrapa.br; bianchet@ cenargen.embrapa.br) 


\section{Introdução}

Desde o trabalho pioneiro de Warming (1892), no final do século XIX, até levantamentos mais recentes (Mendonça et al. 1998), Orchidaceae tem sido apontada como uma das cinco famílias mais representativas da flora do Cerrado. Apesar da importância florística dessa família no bioma, poucos autores têm tratado do tema (Pabst 1971a; Mendonça et al. 1998), de maneira que o conhecimento sobre Orchidaceae nesta região do país é ainda incipiente.

No bioma Cerrado, a área do Distrito Federal (DF) destaca-se em termos de coleta e amostragem. As coletas botânicas na região tiveram início, ainda no século XIX, com o trabalho de naturalistas como Pohl, Saint Hillaire, Glaziou e Ule, que passaram pela área ou pelas proximidades do que hoje compreende o Distrito Federal. Todavia, os trabalhos de exploração e levantamentos sistemáticos da flora local somente tiveram início a partir de 1960, com a fundação de Brasília. Nesta fase, o coletor de Orchidaceae mais expressivo foi Ezechias P. Heringer, que coletou intensivamente na região durante as décadas de 60 e 70 . Destacam-se também neste período, mas em menor proporção, as coletas de Howard S. Irwin e colaboradores. Como especialista destaca-se Guido F. J. Pabst, que examinou e identificou praticamente todo o material originário do Distrito Federal até aquele período. Deste modo, o conhecimento da flora orquidológica do Distrito Federal, até há pouco, esteve fundamentado, basicamente, sobre os trabalhos de coleta de Heringer e de taxonomia de Pabst.

Nas duas últimas décadas, destacam-se as coletas de pesquisadores do IBGE, da EMBRAPA/CENARGEN e de coletores como Anajúlia H. Salles, Zenilton de J. G. Miranda e Rafael S. Oliveira. A partir de 1989 intensificou-se e sistematizou-se o trabalho de coleta dos autores do presente artigo, que já vinham realizando coletas esporádicas desde
1980, e que prosseguem até o presente. Pelo volume de publicações, também deve ser destacada a contribuição de L. C. Menezes, cujo trabalho, no entanto, carece de rigor taxonômico.

A mais completa relação publicada de Orchidaceae para o Distrito Federal é encontrada em Pabst \& Dungs (1975; 1977), onde são apresentados 52 gêneros e 159 espécies. Uma segunda lista, fornecida por Filgueiras \& Pereira (1994), apresenta algumas adições (52 gêneros e 162 espécies), mas muitos erros, tanto ortográficos como taxonômicos. Além destas, há uma série de trabalhos dispersos enfocando florística geral de áreas específicas (p. ex. Pereira et al. 1985; 1993; Maury et al. 1994; Walter \& Sampaio 1998; UNESCO 2000), trabalhos que abordam espécies ou material local (Pabst 1971a; Batista et al. 1993; Romero 1993; Oliveira et al. 1996), novas citações de ocorrências (Pabst 1967a; Bianchetti et al. 1991) e, principalmente, a descrição de espécies novas (Pabst 1964; 1967a; 1967b; 1971b; Menezes 1990; 1991; 1992; 1993; 1995a; 1995b; 1996; 1998; Szlachetko \& Rutkowski 1997; Bianchetti $\&$ Batista 2000). Neste sentido, faltava uma revisão recente que compilasse e atualizasse todos os dados publicados e disponíveis.

Com o objetivo não só de atualizar as listas de Pabst \& Dungs (1975; 1977), mas também registrar resultados de 21 anos de um levantamento sistemático das Orchidaceae no DF, apresenta-se a nova relação de espécies para esta região. Esta nova relação deverá subsidiar a monografia da família para a flora do Distrito Federal.

\section{Material e métodos}

Caracterização do Distrito Federal - O Distrito Federal está localizado entre os paralelos $15^{\circ} 30^{\prime}$ e $16^{\circ} 03^{\prime}$ Sul e os meridianos $47^{\circ} 25^{\prime}$ e $48^{\circ} 12^{\prime}$ 'Oeste, no planalto central do Brasil. Ocupa área de $5.783 \mathrm{~km}^{2}$ e compreende a unidade da federação onde se situa a capital 
brasileira, Brasília. A altitude média da região é de $1.100 \mathrm{~m}$ e os tipos de clima do DF são o tropical com uma estação seca, Aw e tropical de altitude, Cwa e Cwb. O clima da região é marcado por duas estações bem definidas: a) uma estação chuvosa, que vai de outubro a abril, apresentando maior pluviosidade entre dezembro e fevereiro e concentrando mais de $80 \%$ do total anual de chuvas, que oscila entre 1.200 e $1.750 \mathrm{~mm}$; b) uma estação seca, que se estende de maio a setembro, com a umidade relativa do ar variando de $70 \%$ a menos de $20 \%$ no final da estação (Codeplan 1984).

Vegetação do Distrito Federal - Estão presentes, no DF, praticamente todas as fitofisionomias já descritas para o bioma cerrado. De acordo com a terminologia proposta por Ribeiro \& Walter (1998), encontram-se no Distrito Federal formações florestais (matas de galeria, ciliares, seca e cerradão), formações savânicas, principalmente o cerrado sentido restrito com seus quatro subtipos (denso, típico, ralo e rupestre), veredas e palmeirais, até formações campestres (campos sujo, limpo e rupestre). Estimativas indicam que em 1954, antes da inauguração de Brasília, 18,8\% da cobertura vegetal era de mata, $37,8 \%$ de cerrado e $43,2 \%$ de campo (UNESCO, 2000).

Levantamento das Orchidaceae do Distrito Federal - A lista apresentada foi elaborada a partir de três principais fontes: 1) coletas dos autores, realizadas desde 1980 ; 2) exame de materiais herborizados de outros coletores, depositados principalmente nos herbários UB, HB, CEN, IBGE, HEPH, SP e RB; 3) dados bibliográficos.

Para a identificação das espécies, de maneira geral seguui-se o trabalho de Pabst \& Dungs $(1975 ; 1977)$. Para grupos como Physurinae (Garay 1977), Spiranthinae (Garay 1980; Dressler 1993), Pleurothallidinae (Luer 1978; 1982; 1986a; 1986b) e alguns outros casos, foram seguidos trabalhos mais recentes (Christenson 1988; 1996; Wood 1989; Atwood
1993; Hágsater 1993; Romero 1993; CastroNeto \& Campacci 2000; Van den Berg \& Chase 2000; 2001). Para vários táxons não foi possível uma identificação definitiva ao nível específico. A determinação mais precisa destes táxons deverá requerer estudos mais detalhados e será apresentada em outros trabalhos.

\section{Resultados e discussão}

Orchidaceae do Distrito Federal - Na presente lista (Tab. 1) são reconhecidos 72 gêneros, compreendendo 246 espécies, cinco variedades e três formas (254 táxons no total) para o Distrito Federal (DF). Outras oito espécies são consideradas como de possível ocorrência no DF (Tab. 2). Embora não tenham sido comprovadas, há registros para o entorno do DF, sendo possível que venham a ser encontradas dentro dos limites geográficos desta unidade federativa. Foram excluídos 111 táxons (Tab. 3), citados em trabalhos anteriores, dos quais 42 por serem considerados sinônimos e 69 por não estarem relacionados a nenhum material herborizado para o Distrito Federal. Outros quatro táxons de validade duvidosa (Tab. 4) também foram excluídos, até que seja possível avaliá-los melhor.

Os gêneros mais representativos, entendidos tanto pelo número absoluto de espécies que comportam, quanto pelo percentual destes em relação ao total do grupo para o Brasil são: Habenaria (74 espécies, duas variedades e uma forma), Cyrtopodium (17 espécies), Cleistes (13 espécies) e a subtribo Spiranthinae (11 gêneros com 34 espécies, uma variedade e uma forma). Gêneros como Galeandra (seis espécies), Cranichis (três espécies), Liparis (três espécies) e Cyanaeorchis (duas espécies) apresentam menor número de espécies, mas incluem todas, ou grande parte das espécies do gênero de ocorrência no território brasileiro. Gêneros como Epidendrum (oito espécies), Pleurothallis (sete espécies), Oncidium (seis espécies) e Maxillaria (três espécies), 


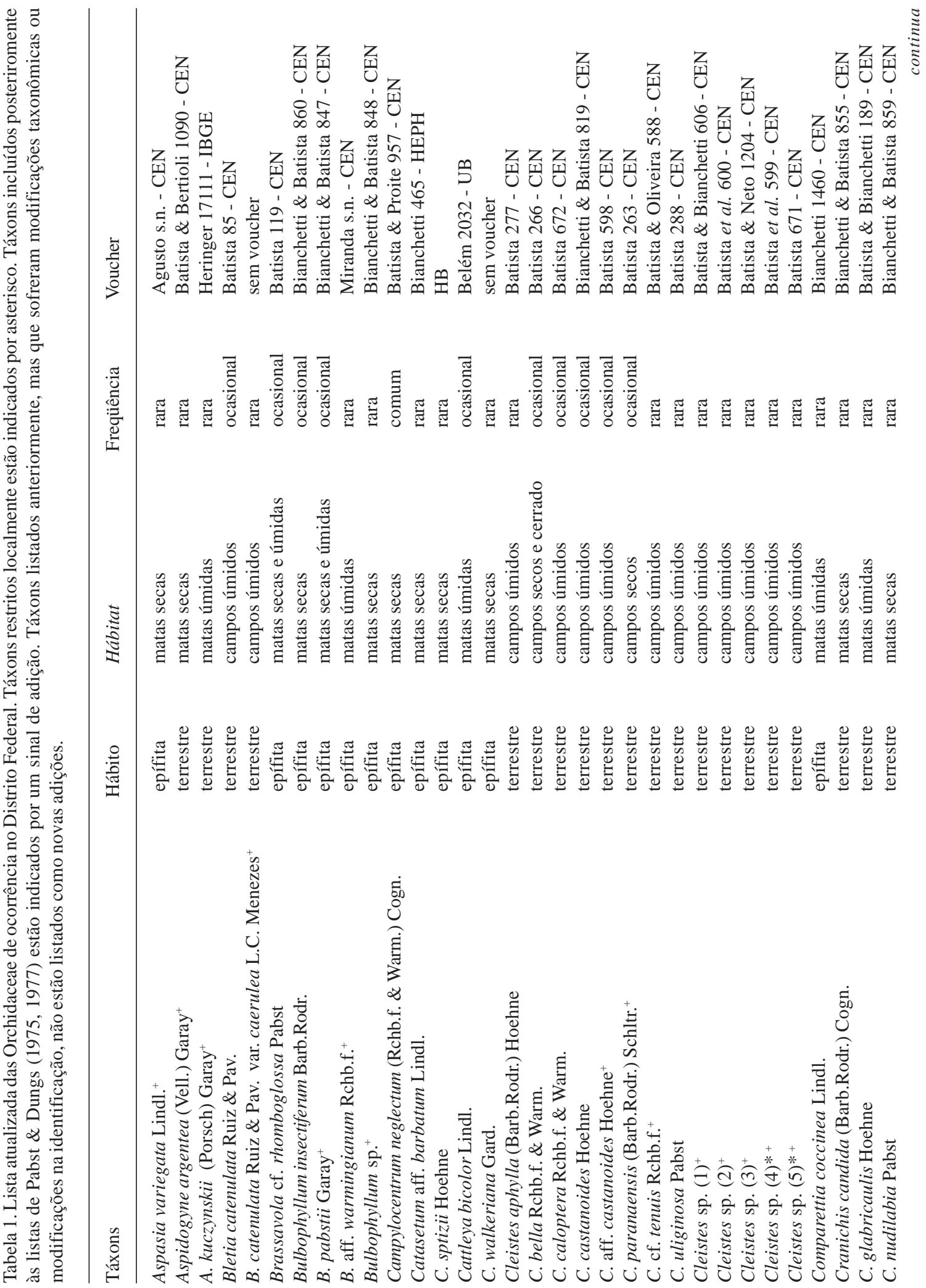


荓总

至总总总总总

总总

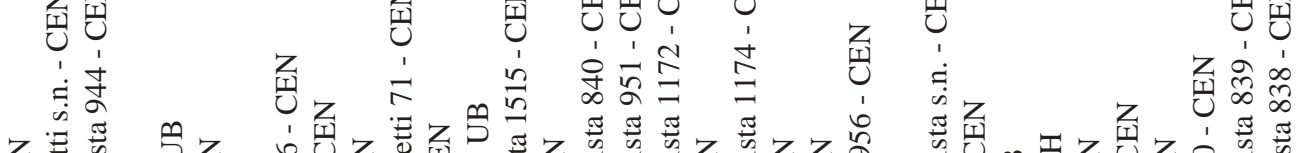

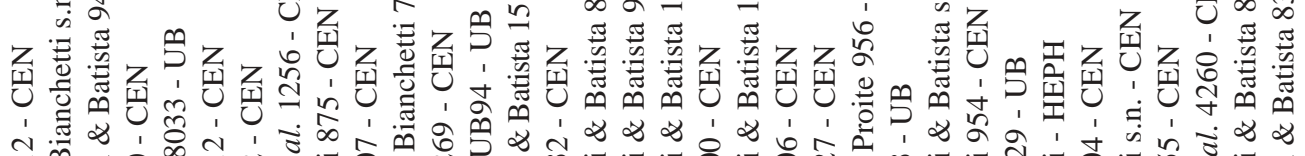

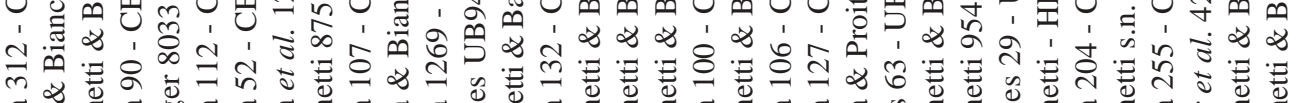

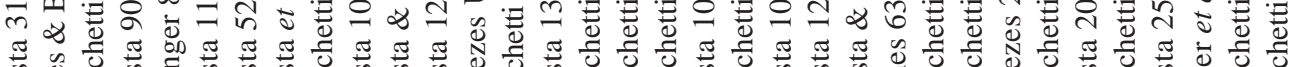

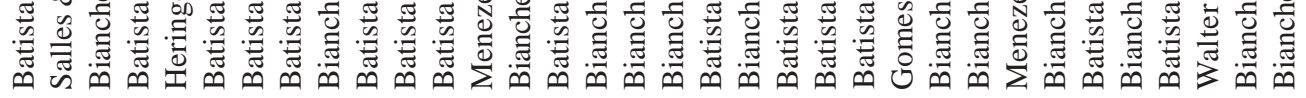

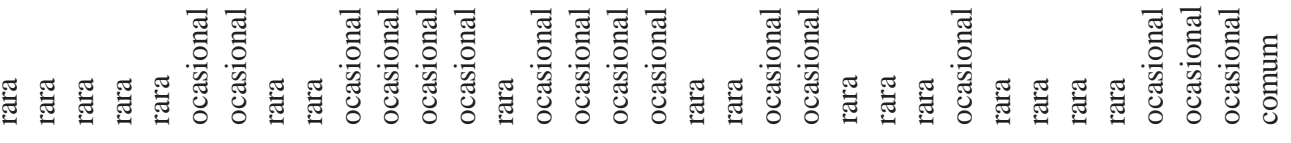<smiles>CCCCCCCC</smiles>

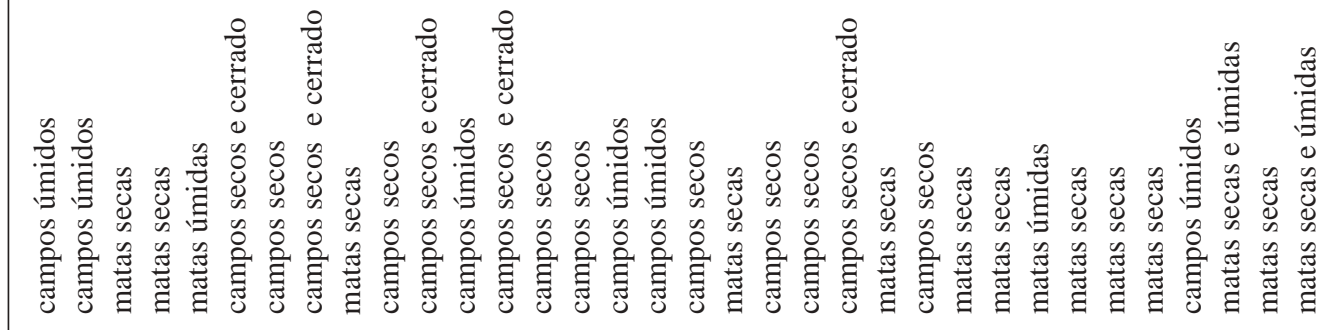

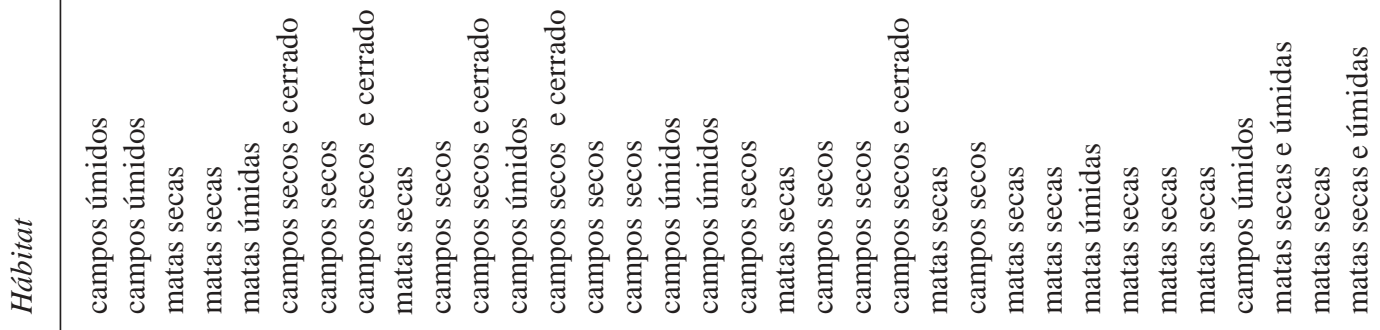

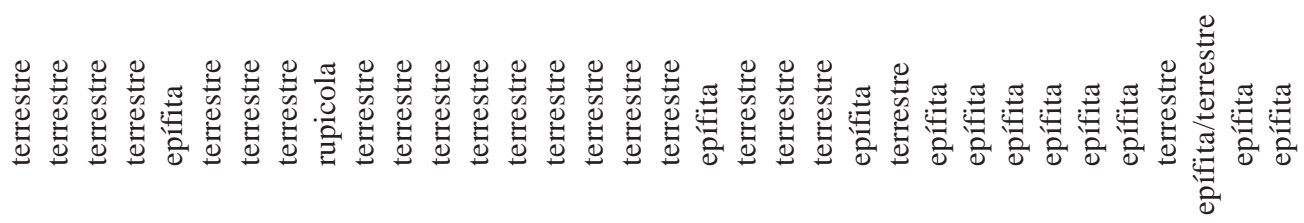

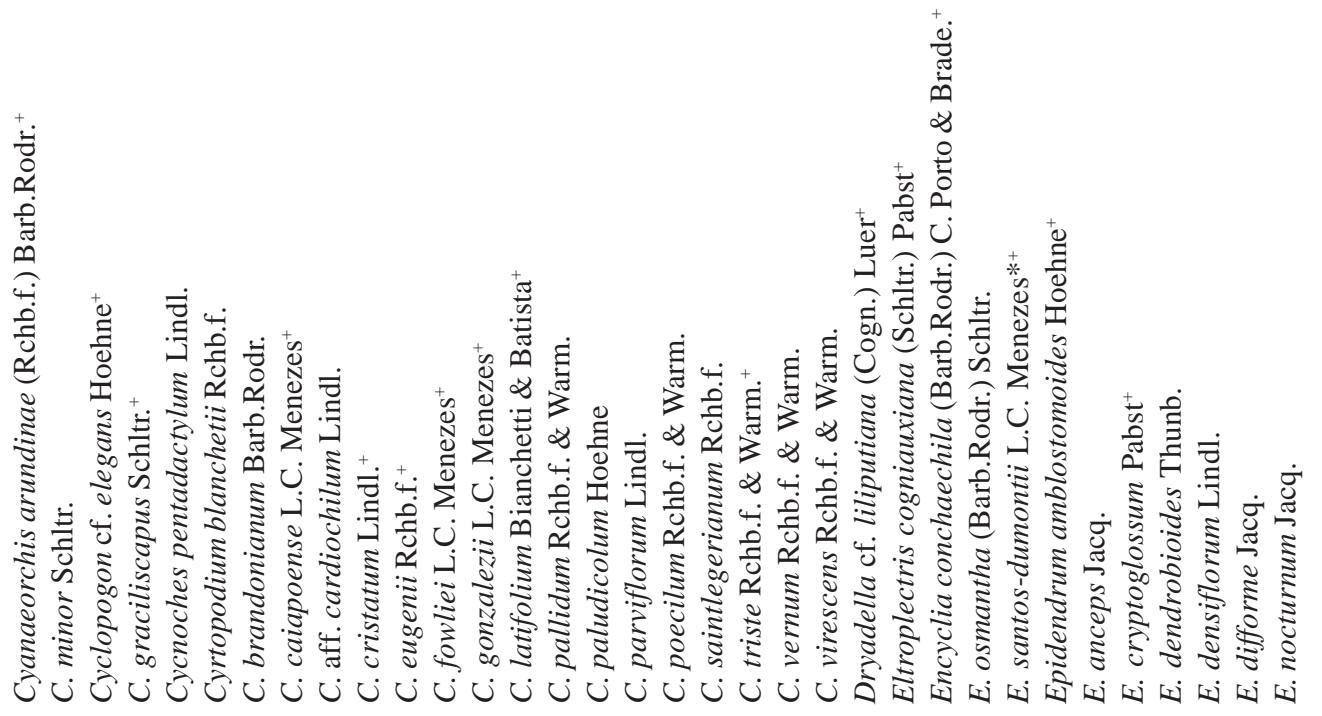




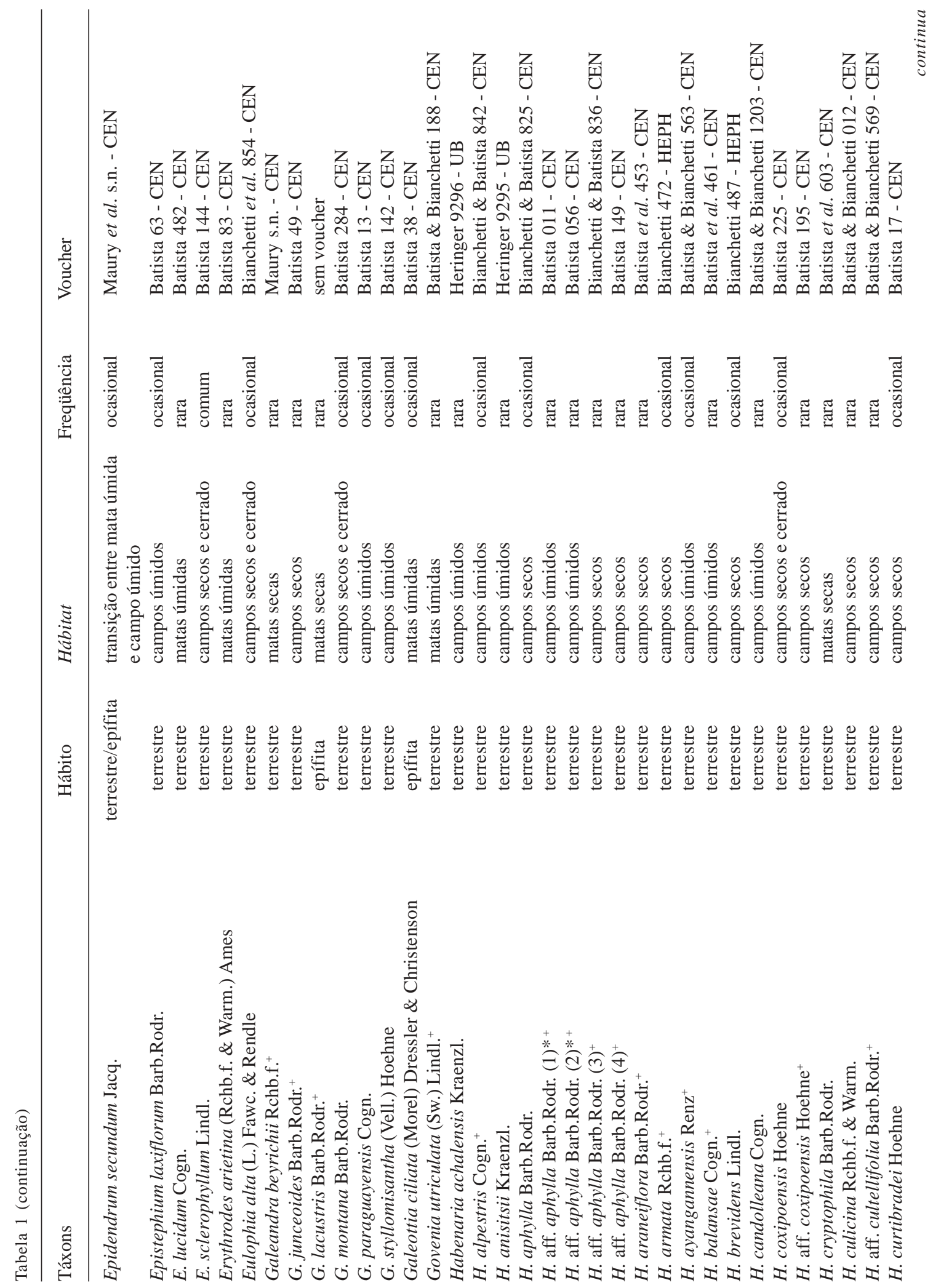




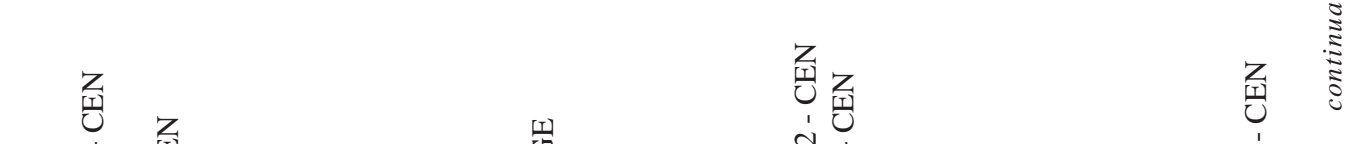

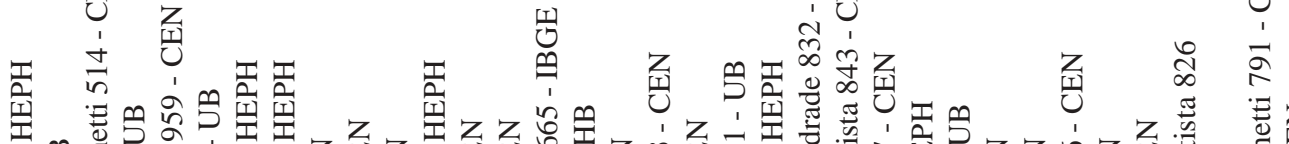

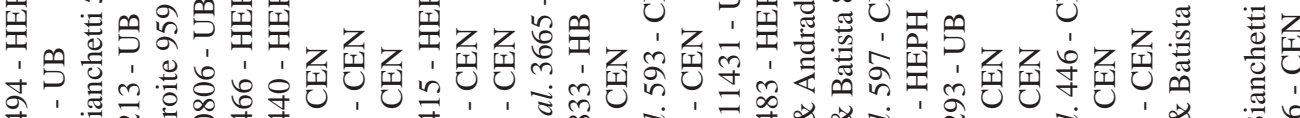

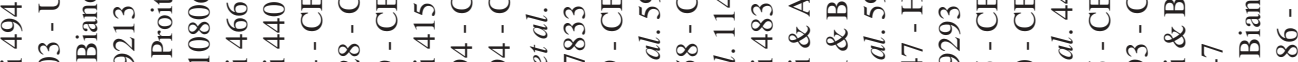

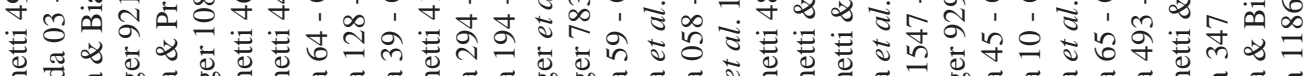

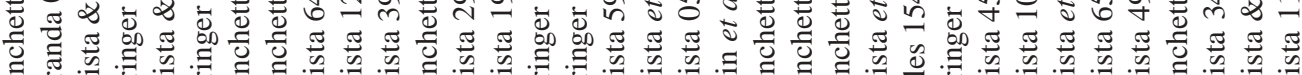

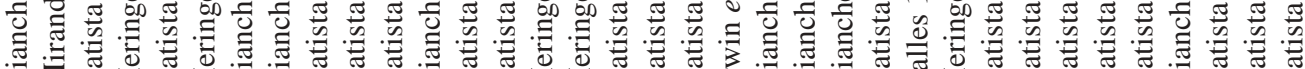

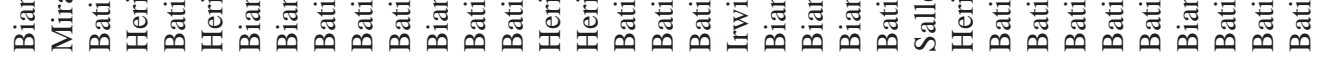

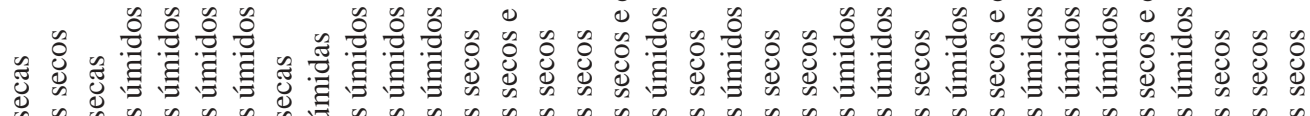<smiles>C1CCCC1</smiles><smiles>[13CH][13CH3]</smiles>

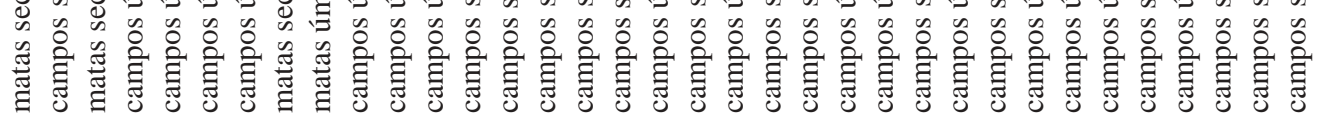

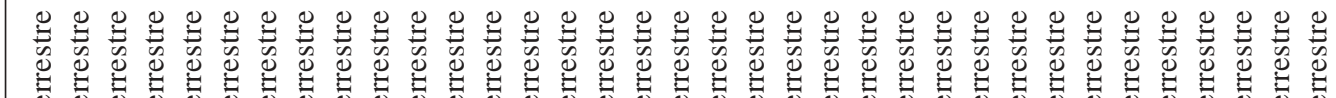

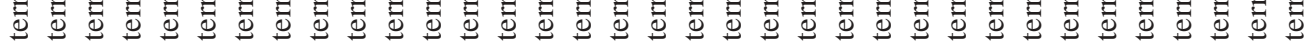

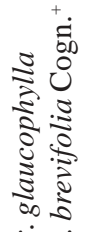

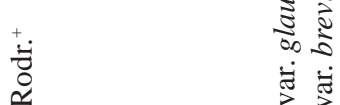

กิ

ตี

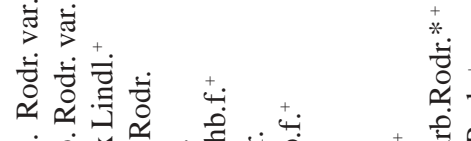

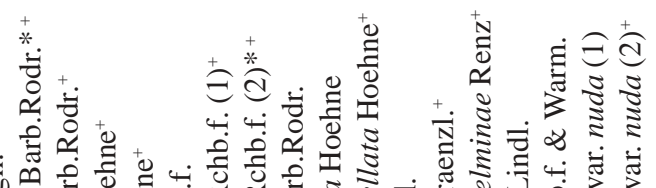

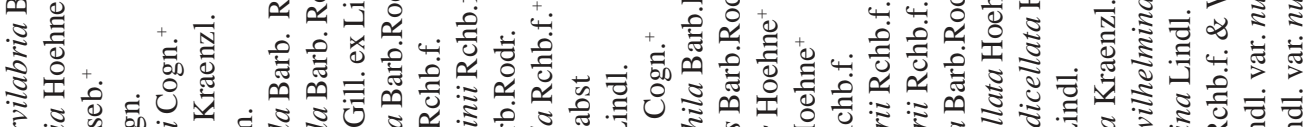

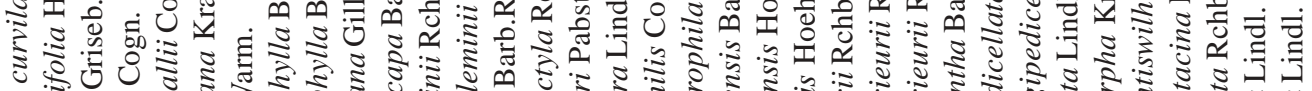

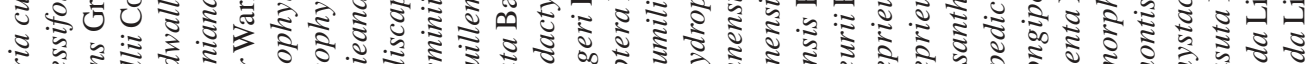

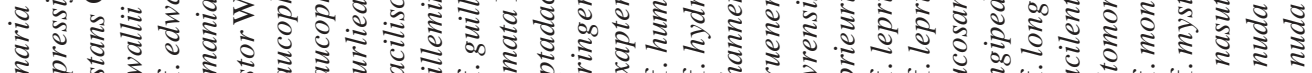

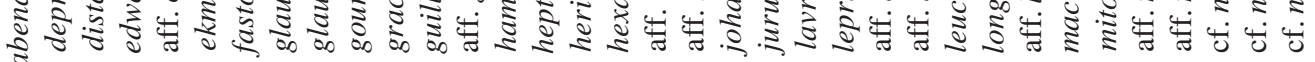

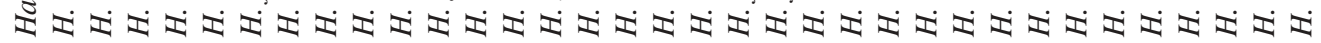




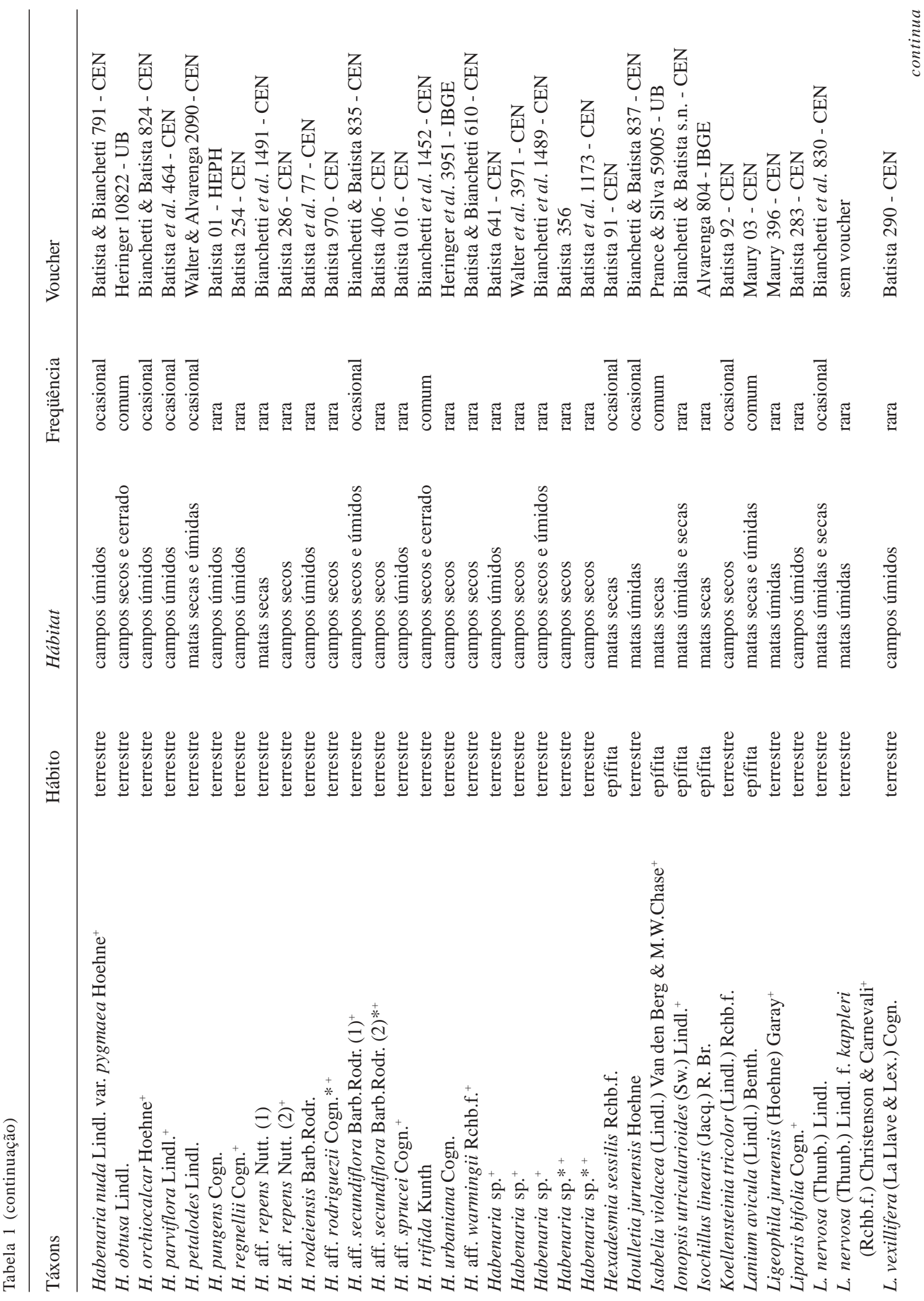




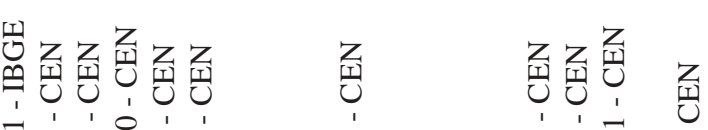

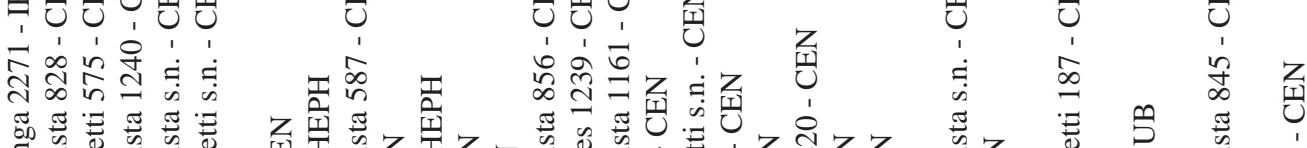

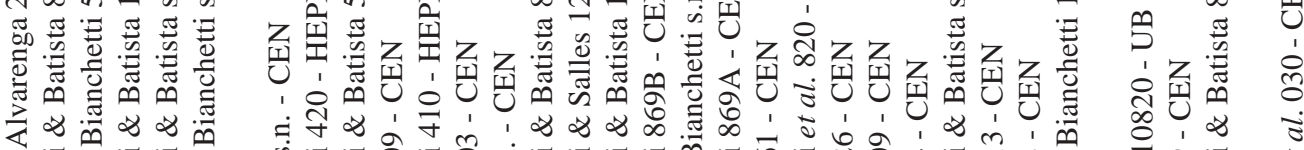
ぬ 告

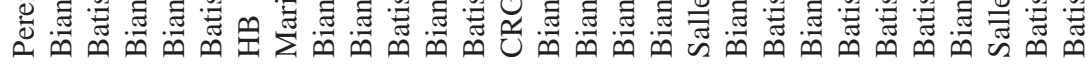

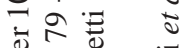

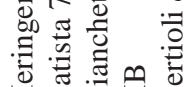

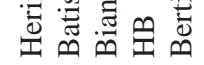

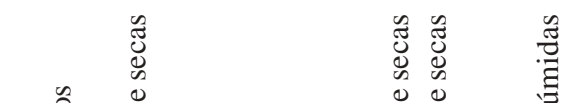

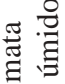

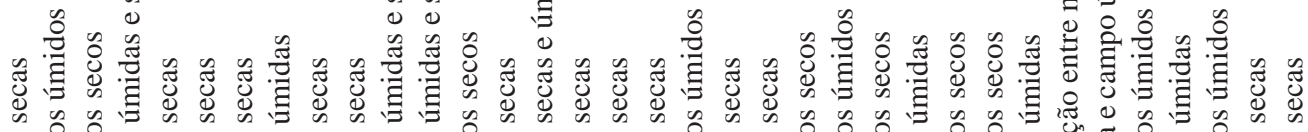

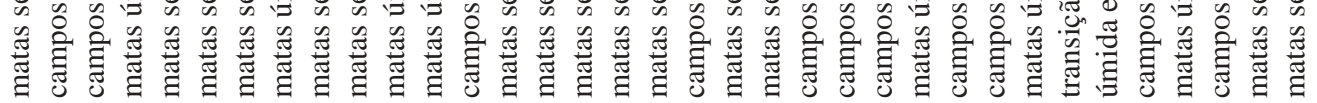




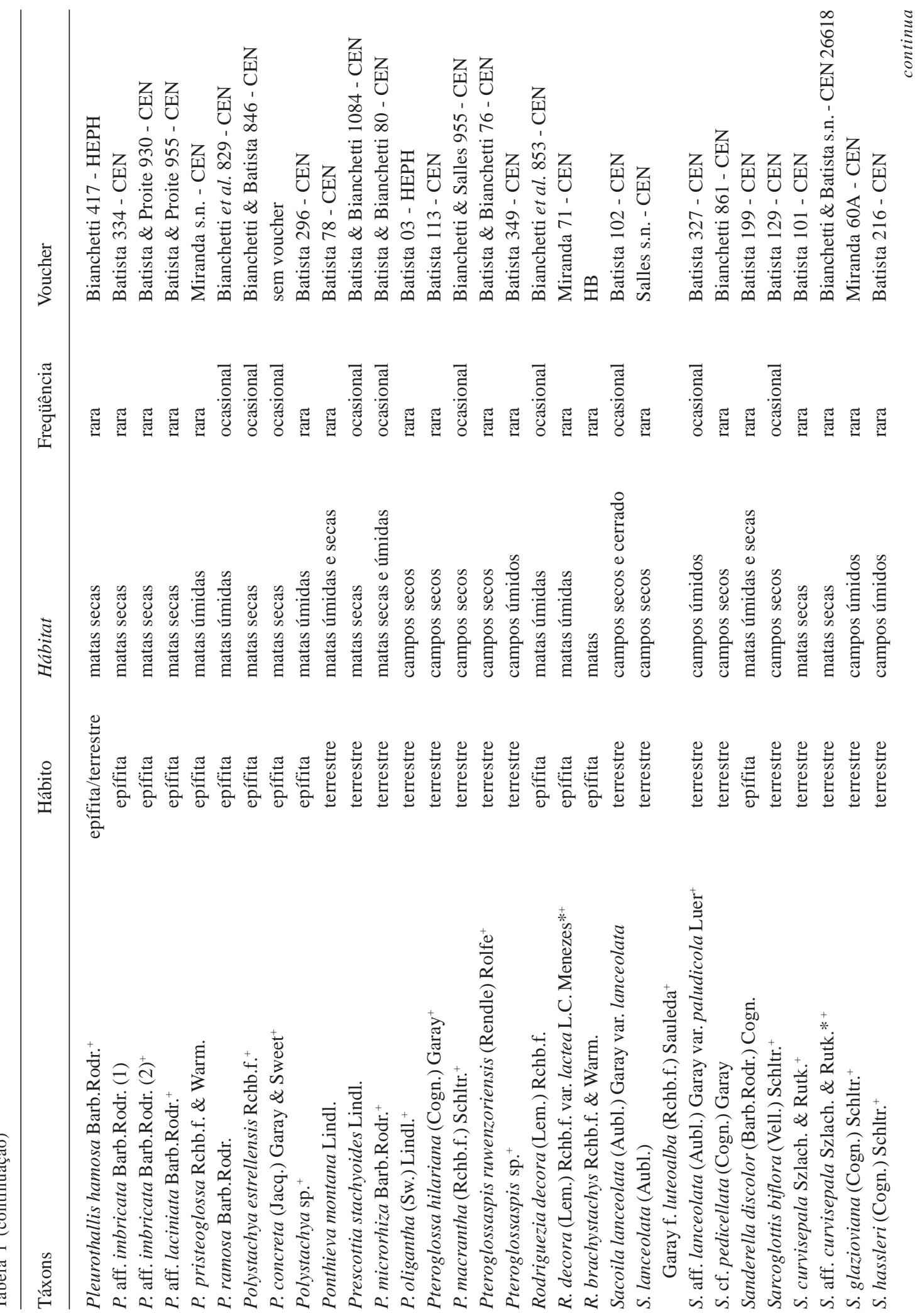




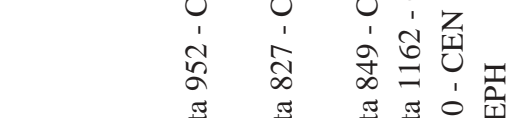

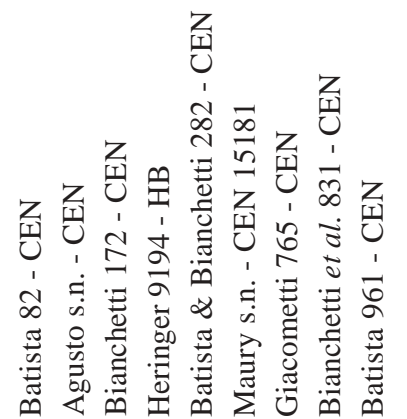

:

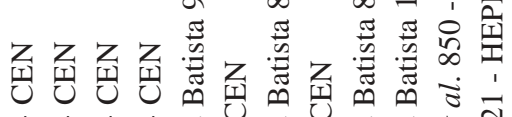
$1,1,1$ U

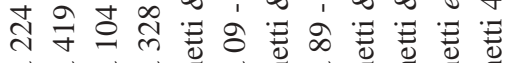

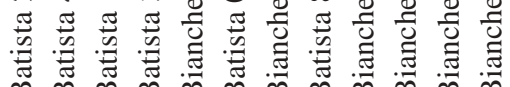

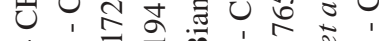

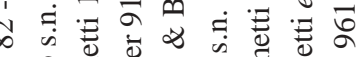

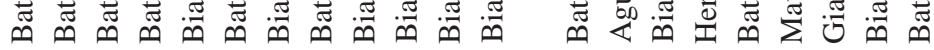

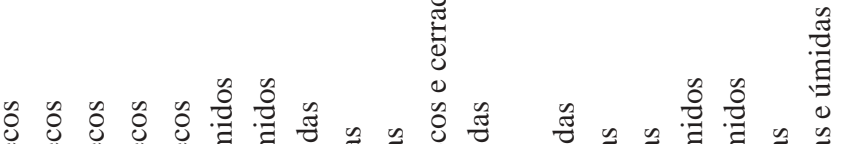

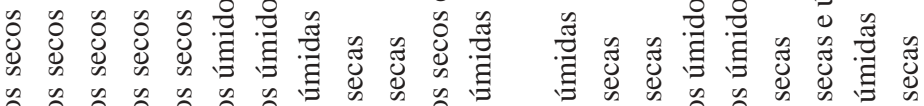

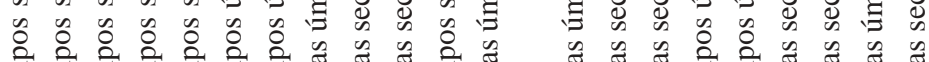

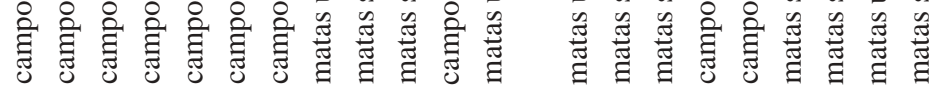

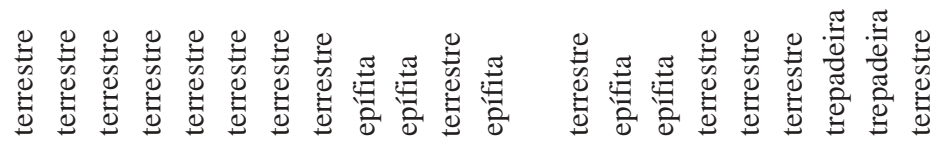

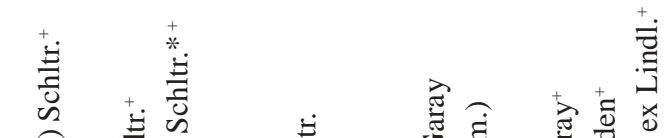

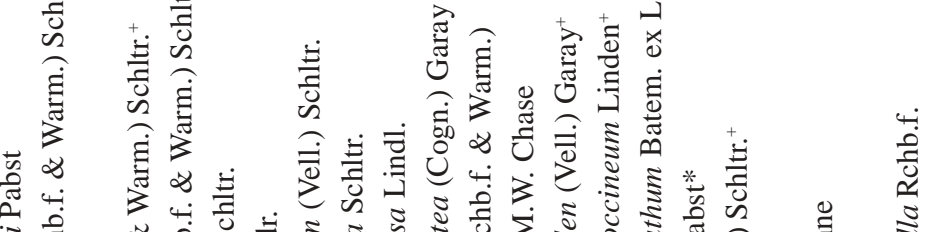

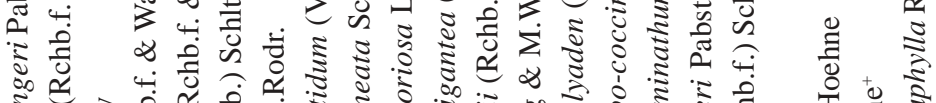

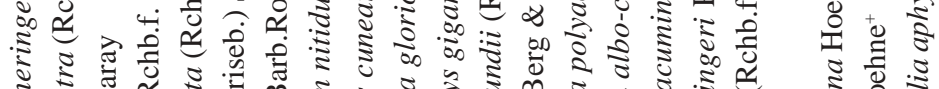
₹

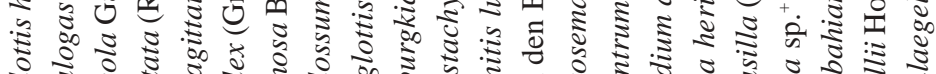

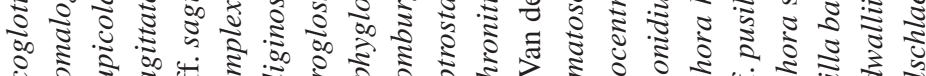

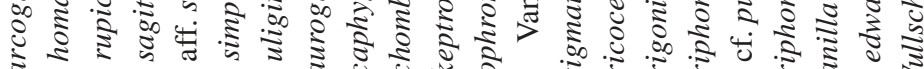

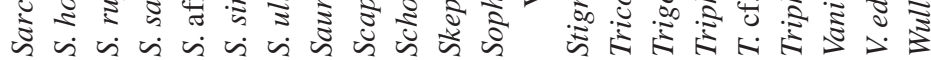


Tabela 2. Táxons de Orchidaceae de possível ocorrência no Distrito Federal.

\section{Táxons}

Campylocentrum micranthum (Lindl.) Rolfe

Catasetum taquariense Bicalho, Barros \& Moutinho

Encyclia argentinensis (Speg.) Hoehne

Encyclia sessiliflora (Edwall) Pabst

Epidendrum rigidum Jacq.

Leucohyle brasiliensis (Cogn.) Schltr.

Macradenia multiflora (Kraenzl.) Cogn.

Oncidium jonesianum Rchb.f.

abundantes na Mata Atlântica no sudeste brasileiro (Barros 1983, 1991; Miller et al. 1994), o bioma brasileiro mais rico em espécies de Orchidaceae (Pabst \& Dungs 1975, 1977), estão pouco representados no DF e outros, como Octomeria e Stelis, também comuns naquelas regiões, estão completamente ausentes. Do mesmo modo, gêneros como Zygopetalum e Bifrenaria, que ocorrem em áreas de campos rupestres ao longo da Cadeia do Espinhaço (Barros 1987; Toscano-de-Brito 1995), também estão ausentes no Distrito Federal e na área nuclear do bioma Cerrado.

Do total de espécies de ocorrência no Distrito Federal, 73,2\% apresentam hábito terrestre e $24,4 \%$ hábito epifitico, o que contrasta marcadamente com a composição florística de Orchidaceae da Mata Atlântica (Barros 1983; 1991; Miller et al. 1994) e da Amazônia (Silva et al. 1995), onde predominam espécies epifíticas (Pabst \& Dungs 1975; 1977). Do restante das espécies de ocorrência no DF, cerca de três espécies (Epidendrum densiflorum, E. secundum e Pleurothallis hamosa) apresentam hábito tanto terrestre como epifitico, uma única espécie é estritamente rupícola (Cyrtopodium aff. cardiochilum) e duas apresentam hábito escandente (Vanilla spp.)

Até o momento foram descritos 18 novos táxons a partir de material proveniente do Distrito Federal, dos quais somente nove foram aqui considerados como válidos. Destes, apenas três
(Encyclia santos-dumontii, Rodriguezia decora f. lactea e Triphora heringeri) ainda parecem ser endêmicos do Distrito Federal. Todos são táxons raros e, até o momento, estão representados apenas pelo material tipo, ou são conhecidos de apenas um único local. Além destes, outros 14 táxons, dos gêneros Cleistes, Habenaria, Lyroglossa e Sarcoglottis, ainda indeterminados ao nível de espécie ou de determinação incerta, também são conhecidos apenas de material proveniente do Distrito Federal. Embora seja provável que alguns sejam de fato restritos a esta unidade federativa, é também possível que uma amostragem maior identifique alguns destes em outras regiões do bioma Cerrado. Na tab. 1, estes 17 táxons aparentemente endêmicos $(6,7 \%)$ aparecem indicados por asteriscos. Outros sete táxons dos gêneros Bulbophyllum, Malaxis, Pelexia, Pleurothallis e Polystachya são também, aparentemente, conhecidos apenas de materiais provenientes do Distrito Federal, mas sua amostragem, ou de táxons afins, ainda é baixa para uma conclusão mais precisa.

Segundo Filgueiras \& Pereira (1994), Orchidaceae é a terceira maior família em número de espécies no DF, mas apesar dessa importância florística, as orquídeas não compõem um elemento dominante da vegetação local e a grande maioria é localmente rara $(61,4 \%)$ ou ocasional $(35 \%)$.

Distribuição das Orchidaceae nas principais formações fitofisionômicas do DF - O DF faz parte do bioma Cerrado. No entanto, a terminologia aplicada para os diferentes tipos fitofisionômicos encontrados no bioma é variada e diversificada. Considerando as dificuldades inerentes ao tema, optou-se por utilizar a terminologia proposta por Ribeiro \& Walter (1998), mas agrupando os tipos fitofisionômicos ali descritos em grupos mais gerais. Assim, para a categoria matas secas, entendam-se as formações florestais com os tipos e subtipos fitofisionômicos de mata de galeria não-inundável, mata seca sempre-verde, semidecídua e 
Tabela 3. Táxons de Orchidaceae e nomes excluídos como de ocorrência no Distrito Federal.

Táxons

Brassavola cebolleta Rchb.f.

B. perrinii Lindl.

Bulbophyllum chloroglossum Rchb.f. \& Warm.

Campylocentrum micranthum (Lindl.) Rolfe

C. robustum Cogn.

Catasetum fimbriatum (Morren) Lindl.

Cattleya nobilior Rchb.f.

Cleistes cipoana Hoehne

C. revoluta (Barb.Rodr.) Schltr.

C. rosea Lindl.

Cranichis scripta Kraenzl.

Cyclopogon aphyllus Schltr.

C. chloroleucus Barb.Rodr.

Cyrtopodium andersonii $\mathrm{R}$. Br.

C. aureum L.C. Menezes

C. dusenii Schltr.

C. falcilobum Hoehne \& Schltr.

C. galeandroides Cogn.

C. lissochiloides Hoehne \& Schltr.

C. paranaense Schltr.

C. virens Rchb.f. \& Warm.

Encyclia linearifolioides (Kraenzl.) Hoehne

E. longifolia (Barb.Rodr.) Rchb.f.

E. lutzenbergerii L.C. Menezes

E. ensiformis (Ruiz \& Pav.) Mansf.

E. odoratissima (Lindl.) Schltr.

Epidendrum ansiferum Rchb.f.

E. aquaticum Lindl.

E. crassifolium Lindl.

E. ellipticum Grah.

E. elongatum Jacq.

E. floribundum Kunth

E. paniculatum Ruiz \& Pavon

Epistephium parviflorum Lindl.

E. praestans Hoehne

Erythrodes debilis (Lindl.) Ames

E. juruensis (Hoehne) Ames

E. kuczynskii (Porsch) Garay

E. paranaensis (Kraenzl.) Pabst

Eulophidium maculatum (Lindl.) Pfitz.

Eurystyles actinosophila (Barb.Rodr.) Schltr.

Galeandra graminoides Barb.Rodr.

G. lagoensis Rchb.f. \& Warm.

Gomesa foliosa (Hook.) Kl. \& Rchb.f.

Habenaria amambayensis Schltr.

H. caldensis Kraenzl.

H. confusa Cogn.

H. crassipes Schltr.

H. culmiformis Hoehne

H. duckeana Schltr.
Fonte ou nome válido

Pabst \& Dungs (1975)

UNESCO (2000)

Pabst \& Dungs (1975)

Bianchetti et al. (1991)

Pabst \& Dungs (1975)

Pabst \& Dungs (1975)

Pabst \& Dungs (1975)

Bianchetti et al. (1991)

Bianchetti et al. (1991)

Pabst \& Dungs (1975)

Pabst \& Dungs (1975)

$=$ Pelexia goyazensis $($ Cogn.$)$ Garay

= Stigmatosema polyaden (Vell.) Garay

Pabst \& Dungs (1975)

= C. vernum Rchb.f. \& Warm.

Bianchetti et al. (1991)

$=C$. parviflorum Lindl.

= Pteroglossaspis ruwenzoriensis (Rendle) Rolfe

Pabst \& Dungs (1975)

Pabst \& Dungs (1975)

$=C$. virescens Rchb.f. \& Warm.

$=$ E. conchaechila (Barb.Rodr.) C. Porto \& Brade

Pabst \& Dungs (1975)

$=$ E. osmantha (Barb.Rodr.) Schltr.

Bianchetti et al. (1991)

Pereira et al. (1993)

Pabst \& Dungs (1975)

Pabst \& Dungs (1975)

Pabst \& Dungs (1975)

Bianchetti et al. (1991)

$=$ E. secundum Jacq.

$=E$. densiflorum Lindl.

$=$ E. densiflorum Lindl.

Pabst \& Dungs (1975)

$=$ E. sclerophyllum Lindl.

$=$ Platythelys debilis (Lindl.) Garay

= Ligeophila juruensis (Hoehne) Garay

= Aspidogyne kuczynskii (Porsch) Garay

= Platythelys paranaensis (Kraenzl.) Garay

= Oeceoclades maculata (Lindl.) Lindl.

Filgueiras \& Pereira (1994)

Pabst \& Dungs (1975)

= G. montana Barb.Rodr.

Pabst \& Dungs (1977)

Pabst \& Dungs (1975)

Bianchetti et al. (1991)

Pabst \& Dungs (1975)

Pabst \& Dungs (1975)

$=H$. leprieurii Rchb.f.

Pabst (1971a) 
Tabela 3 (continuação)

Táxons

Habenaria dusenii Schltr.

H. ernesti-ulei Hoehne

$H$. fastor Warm. ex Hoehne

H. glazioviana Kraenzl.

H. goyazensis Cogn.

H. gracilis Lindl.

H. inconspicua Cogn.

H. lagunaesanctae Kraenzl.

H. lancipetala Pabst

H. lasioglossa Cogn.

H. leaoana Schltr.

H. nemorosa Barb.Rodr.

H. ornithoides Barb.Rodr.

H. ouro-branquensis Hoehne

H. pickelii Hoehne

H. pseudocaldensis Kraenzl.

H. renzii Sprunger

$H$. retusa Barb.Rodr.

H. rudolfi-schlechteri Hoehne

H. rupicola Barb.Rodr.

$H$. secunda Lindl.

$H$. setacea Lindl.

H. staminodiata Schltr.

$H$. vaupelli Rchb.f. \& Warm.

$H$. verecunda Schltr.

Koellensteinia altissima Pabst

Laelia lundii Rchb.f. \& Warm.

Lanium berkeleyi Rolfe.

Lockhartia lunifera (Lindl.) Rchb.f.

Lyroglossa bradei Schltr.

Mendoncella ciliata (Morel) Garay

Mesadenella esmeraldae (Linden \& Rchb.f.) Pabst \& Garay

Oncidium orthostates Ridl.

O. varicosum Lindl.

Ornithidium parviflorum (Poeppig \& Endl.) Rchb.f.

Pelexia laminata Schltr.

P. minarum (Kraenzl.) Schltr.

P. orthosepala (Rchb.f. \& Warm.) Schltr.

$P$. viridis (Cogn.) Schltr.

Pleurothallis barbulata Lindl.

P. limbata Cogn.

P. nemorosa Barb.Rodr.

P. warmingii Rchb.f.

Polystachya foliosa (Lindl.) Rchb.f.

P. geraensis Barb.Rodr.

Pteroglossaspis eustachya Rchb.f.

Sarcoglottis fasciculata (Vell.) Schltr.

S. gonzalezii L.C. Menezes

$S$. rupestris Barb.Rodr.

S. viscosus Szlach. \& Rutk.
Fonte ou nome válido

Pabst \& Dungs (1975)

Bianchetti et al. (1991)

Pabst \& Dungs (1975)

Bianchetti et al. (1991)

Pabst \& Dungs (1975)

Pabst \& Dungs (1975)

Bianchetti et al. (1991)

Bianchetti et al. (1991)

$=H$. orchiocalcar Hoehne

Pabst \& Dungs (1975)

$=$ H. sprucei Cogn.

Pabst \& Dungs (1975)

= H. obtusa Lindl.

Pabst \& Dungs (1975)

Pabst (1971a)

Bianchetti et al. (1991)

$=$ H. balansae Cogn.

Pabst \& Dungs (1975)

Bianchetti et al. (1991)

Pabst \& Dungs (1975)

Pabst \& Dungs (1975)

Bianchetti et al. (1991)

$=H$. macilenta (Lindl.) Rchb.f.

$=$ H. johannensis Barb.Rodr.

Pabst \& Dungs (1975)

Bianchetti et al. (1991)

= Sophronitis lundii (Rchb.f. \& Warm.) Van den

Berg \& M.W. Chase

$=$ L. avicula (Lindl.) Benth

Bianchetti et al. (1991)

= Pteroglossa hilariana (Cogn.) Garay

= Galeottia ciliata (Morel) Dressler \& Christenson

= Mesadenella cuspidata (Lindl.) Garay

Pereira et al. (1993)

UNESCO (2000)

= Maxillaria parviflora (Poeppig \& End1.) Garay

Pabst \& Dungs (1975)

Pabst \& Dungs (1975)

Pabst \& Dungs (1975)

Pabst \& Dungs (1975)

Bianchetti et al. (1991)

Pabst \& Dungs (1975)

Bianchetti et al. (1991)

= Myoxanthus lonchophyllus (Barb.Rodr.) Luer

Pabst \& Dungs (1975)

Pabst \& Dungs (1975)

Bianchetti et al. (1991)

Pabst \& Dungs (1975)

= S. curvisepala Szlach. \& Rutk.

$=$ S. rupicola Garay

$=S$. heringeri Pabst 
Tabela 3 (continuação)

Táxons

Schomburgkia crispa Lindl.

Sophronitella violacea (Lindl.) Schltr.

Sophronitis cernua Lindl.

Stenorrhynchos arechavaletanii Barb.Rodr.

S. latipetalus Cogn.

S. acianthiformis (Rchb.f. \& Warm.) Cogn.

S. giganteus Cogn.

S. lanceolatus (Aubl.) L.C. Rich.

S. lanceolatus (Aubl.) L.C. Rich. var. luteoalbus Rchb. f.

S. pedicellatus Cogn.

Vanilla chamissonis Kraenzl.
Fonte ou nome válido

$=$ S. gloriosa Lindl.

= Isabelia violacea (Lindl.) Van den Berg \& M.W.Chase

Filgueiras \& Pereira (1994)

Bianchetti et al. (1991)

Bianchetti et al. (1991)

= Nothostele acianthiformis (Rchb.f. \& Warm.)

Garay

$=$ Skeptrostachys gigantea $(\operatorname{Cogn}$.) Garay

= Sacoila lanceolata (Aubl.) Garay

= Sacoila lanceolata (Aubl.) Garay f. luteoalba

(Rchb.f.) Sauleda

= Sacoila pedicellata (Cogn.) Garay

Pabst \& Dungs (1975) decídua; por matas úmidas, entenda-se o tipo fitofisionômico de mata de galeria inundável; por cerrado entendam-se as formações savânicas com os tipos e subtipos fitofisionômicos de cerrado denso, típico e ralo; por campos secos entendam-se as formações campestres com os tipos e subtipos fitofisionômicos de campo sujo seco, campo sujo seco com murundus, campo limpo seco, campo limpo seco com murundus; por campos úmidos entendam-se as formações campestres estacionais ou permanentemente úmidas com os tipos e subtipos fitofisionômicos de campo sujo úmido, campo sujo úmido com murundus, campo limpo úmido e campo limpo úmido com murundus.

Do total de espécies de ocorrência no DF, 148 (58\%) ocorrem em formações savânicas e campestres, 104 (41\%) em formações florestais e duas espécies, Epidendrum secundum e Pelexia aff. pterygantha, ocorrem preferencialmente na área de transição entre a mata e o campo. Em geral esta separação é bem definida e pouquíssimas espécies ocorrem tanto em formações savânicas e campestres como em florestais. Entre os poucos exemplos pode-se citar Pteroglossa macrantha, que embora seja muito mais comum em campos secos, já foi observada no interior de matas secas. Das diversas fitofisionomias de ocorrência no DF, a que abriga o maior número de espécies de Orchidaceae é a dos campos úmidos, com cerca de 69 táxons $(27 \%$ do total do DF). São características dos campos úmidos do DF diversas espécies de Habenaria e Cleistes, algumas espécies de Cyrtopodium, Galeandra, Sarcoglottis, Pelexia, Lyroglossa, Liparis,

Tabela 4. Táxons citados para o Distrito Federal, mas de validade taxonômica incerta ou duvidosa.

Táxons

Nome válido

Cyrtopodium paludicolum Hoehne var. reginae Pabst

Cyrtopodium vernum Rchb.f. \& Warm. var. fulvum L.C. Menezes

Cyrtopodium withnerii L.C. Menezes

Oncidium hydrophilum Barb.Rodr. var. immaculatum L.C. Menezes

= Cyrtopodium poecilum Rchb.f. \& Warm. var. fulvum (L.C. Menezes) L.C. Menezes

= Oncidium hydrophilum Barb.Rodr. f. immaculatum (L.C. Menezes) E.A. Christenson 
Epistephium e os gêneros Bletia, Cyanaeorchis, Platythelys e Phragmipedium.

A segunda fitofisionomia com o maior número de espécies é a dos campos secos, com cerca de 59 táxons. São particularmente freqüentes nesses campos diversas espécies de Cyrtopodium e Habenaria, algumas espécies de Galeandra, Cleistes, Sarcoglottis, Pelexia, Sacoila, Lyroglossa, Pteroglossa, Skeptrostachys, além de Epistephium sclerophyllum e Eulophia alta, entre outras. Algumas poucas espécies, principalmente no gênero Habenaria, podem ocorrem tanto em formações de campos úmidos como secos. Das espécies de ocorrência em formações campestres, todas são terrestres. O cerrado típico ou formações com o dossel ainda mais fechado como o cerradão, são, de maneira geral, pobres em espécies de orquídeas; das cerca de 17 espécies terrestres registradas para essas fitofisionomias, todas são mais frequientes em campos secos que ocasionalmente ocorrem no cerrado típico. No DF, foi encontrada uma única espécie epifítica ocorrendo em cerrado típico (Catasetum aff. barbatum). Em áreas de transição cerrado/ cerradão ou cerradão/mata seca podem ser encontradas algumas outras poucas espécies epifíticas como Scaphyglottis cuneata e Isabelia violacea.

Das formações florestais, a que abriga o maior número de espécies são as matas secas, onde podem ser encontradas cerca de 60 espécies (23,6\% do total do DF), principalmente epifíticas dos gêneros Epidendrum, Oncidium e Pleurothallis e, em menor proporção, dos gêneros Bulbophyllum, Campylocentrum, Encyclia, Isabelia, Maxillaria, Notylia, Polystachya, Scaphyglottis, Lockhartia e Plectrophora, entre outros. Entre as terrestres, destacam-se os gêneros Cranichis, Malaxis, Mesadenella, Prescottia e Cyclopogon. Nas matas secas, as espécies de hábito epifítico predominam (39 espécies) sobre as terrestres (cerca de 19 espécies). Em segundo lugar aparecem as matas úmidas, que abrigam cerca de 28 espécies. Entre as epifíticas mais características ou freqüentes destacam-se Cattleya bicolor, Rodriguezia decora e Galeottia ciliata e, entre as terrestres, Erythrodes arietina, Sauroglossum nitidum, Houlletia juruensis, Pelexia hypnophila e P. pterygantha. Nas matas úmidas a proporção entre espécies de hábito terrestre e epifítico é similar, cerca de 13 espécies em cada. Esta diferença em relação às matas secas aparentemente deve-se à estrutura de algumas matas inundáveis, que apresentam o dossel mais baixo e aberto, permitindo a passagem de mais luz para os estratos inferiores e o desenvolvimento de vegetação herbácea mais diversificada. Cerca de 16 espécies ocorrem tanto em matas úmidas quanto em matas secas. Estas estão representadas, basicamente, por espécies epifíticas nos gêneros Brassavola, Bulbophyllum, Ionopsis, Lanium, Macroclinium e Mormodes.

Comparação da listagem atual com levantamentos anteriores - Em relação ao principal levantamento anterior (Pabst \& Dungs 1975; 1977) a listagem ora apresentada representa um acréscimo em termos de valores numéricos gerais, de 95 táxons (37\% do total), incluindo 17 novos gêneros para o DF. Destes, a grande maioria está representada por espécies coletadas posteriormente aos trabalhos de Pabst \& Dungs (1975; 1977), enquanto alguns, como Govenia e Sophronitella (= Isabelia), já constavam de material examinado e identificado por Pabst, mas que não foram incluídos. Outros nove gêneros que não constam nos trabalhos de Pabst \& Dungs (1975; 1977), representam táxons já citados mas que sofreram alguma modificação taxonômica. A inclusão do gênero Gomesa bem como de Cyrtopodium paranaense para o DF por Pabst \& Dungs (1975; 1977) é, certamente, um engano, e deve representar uma confusão entre a cidade do Rio de Janeiro (estado da Guanabara) que até 1960 sediava a capital do país e correspondia ao Distrito Federal. A lista de Filgueiras \& Pereira 
(1994) representa, basicamente, uma compilação dos dados presentes em Pabst \& Dungs (1975; 1977), adicionados de algumas poucas novas citações provenientes de material herborizado. A inclusão de Eurystyles actinosophila e Sophronitis cernua neste último trabalho é certamente um equívoco, uma vez que o material utilizado para as citações, localizado no herbário do Jardim Botânico de Brasília (HEPH), é proveniente de Patrocínio, Minas Gerais. Os 17 gêneros mencionados, bem como a coleta de espécies não registradas anteriormente, principalmente nos gêneros Habenaria, Cleistes, Cyrtopodium e diversos gêneros da subtribo Spiranthinae, respondem pela quase totalidade das adições incluídas neste trabalho.

Este aumento é resultado da continuidade de coletas botânicas na região direcionadas para Orchidaceae e de um minucioso trabalho taxonômico. Há mais de 30 anos Pabst (1971a) afirmou: "O mérito de termos podido registrar um número tão elevado de orquídeas para o Distrito Federal cabe ao Eng. Agr. Ezechias P. Heringer, o qual, residindo em Brasília, teve a oportunidade de coletar sistematicamente em todas as áreas do DF, durante várias épocas do ano e durante anos seguidos. ... Hoje, não é fácil encontrar uma espécie nova para o DF". Ressalte-se que, desde então, cerca de 129 novas citações já foram acrescidas à lista do DF e, certamente, há espécies ainda por serem descobertas na região. Várias áreas com potencial para a flora orquidológica, como o Parque Nacional de Brasília, o Jardim Botânico de Brasília, a Chapada da Contagem e as matas mesofíticas do noroeste do DF, ainda não foram bem amostradas, e mesmo áreas já bem coletadas, ainda continuam revelando algumas surpresas, como no caso da Fazenda Sucupira. Desde a publicação da primeira compilação para o local há três anos (Walter \& Sampaio 1998), 37 espécies já foram acrescidas à relação inicial de 31 espécies, incluindo um gênero novo (Dryadella) para o bioma Cerrado e mais três novas citações de ocorrências para o DF.
As Orchidaceae do DF e seu contexto no Cerrado - Considerando a relação total de 493 táxons de Orchidaceae apresentada para o Cerrado por Mendonça et al. (1998), no DF estão presentes $51,3 \%$ do total citado para o bioma. Considerando que o Distrito Federal representa apenas cerca de 0,3\% da área total do Cerrado, este valor indica uma riqueza notável para esta região, sendo o DF o local com o maior número conhecido de espécies de orquídeas neste bioma. Da relação apresentada por Mendonça et al. (1998), estão ausentes do DF, 28 gêneros. A grande maioria corresponde a gêneros com maior número de representantes na Mata Atlântica, que penetram nas regiões limítrofes com o cerrado e os campos rupestres do sudeste brasileiro, como Bifrenaria, Brachystele, Capanemia, Centroglossa, Lankesterella, Leptotes, Masdevallia, Octomeria, Pseudolaelia, Saundersia, Scuticaria e Zygopetalum, entre alguns outros, mas que aparentemente não alcançam a região nuclear do cerrado. Outros como Prostechea, Leucohyle, Macradenia, Orleanesia, Ornithocephalus e Xylobium ocorrem na região nuclear do cerrado, mas ainda não foram registrados para o DF.

A representatividade do DF para Orchidaceae do cerrado é, aparentemente, resultante da combinação tanto de amostragem, uma vez que o DF é, sem dúvida, o local mais bem coletado dentro do bioma, como, de fato, da riqueza local em espécies. Predominam no DF principalmente espécies terrestres dos gêneros Habenaria, Cyrtopodium, Cleistes, Galeandra e diversos gêneros de Spiranthinae, grupos que são particularmente favorecidos por condições encontradas em ambientes abertos e de maiores altitudes. Outros locais no bioma Cerrado, localizados a uma altitude média superior a 1000 m, como a Serra dos Pirineus e a Chapada dos Veadeiros em Goiás, também são particularmente ricos em espécies de alguns destes gêneros citados.

O levantamento completo das Orchidaceae e mesmo da flora geral do DF é hoje uma corrida 
contra o tempo, em função da expansão urbana e rural, que se acelerou muito nas últimas décadas. Várias áreas que mantinham remanescentes significativos de vegetação nativa desde a fundação de Brasília, desapareceram nos últimos anos, e continuam desaparecendo rapidamente. Em UNESCO (2000) registra-se que, em apenas 44 anos (avaliação de 1954 a 1998), o DF perdeu 57,6\% da sua cobertura vegetal e que a categoria cerrado foi a mais atingida, com $73,8 \%$ de perdas. Este levantamento também se ressente de recursos financeiros e do pequeno número de botânicos e orquidófilos interessados em taxonomia de Orchidaceae. Estes fatores, associados ao pequeno apelo que as espécies nativas menos ornamentais apresentam, embora correspondam à grande maioria das espécies locais, fazem prever uma redução acentuada da enorme riqueza desta família no Distrito Federal.

\section{Agradecimentos}

A Bruno M.T. Walter, pela leitura crítica, sugestões e revisão do artigo. Aos curadores dos herbários UB, HB, IBGE, HEPH, SP e RB, pelos empréstimos ou acesso às suas coleções. A todos as pessoas que tem contribuído para o levantamento das Orchidaceae do Distrito Federal, em especial a Cilulia M. Maury, Anajúlia H. Salles, Zenilton de J.G. Miranda e Rafael S. Oliveira.

\section{Referências bibliográficas}

Atwood, J. T. 1993. A revision of the Maxillaria neglecta complex (Orchidaceae) in Mesoamerica. Lindleyana 8(1): 25-31.

Barros, F. 1983. Flora fanerogâmica da reserva do Parque Estadual das Fontes do Ipiranga (São Paulo, Brasil). 198 - Orchidaceae. Hoehnea 10: 74-124.

Barros, F. 1987. Orchidaceae. Pp. 125-130. In: A.M. Giulietti, N.L. de Menezes, J.R. Pirani, M. Meguro \& M.G.L. Wanderley (Eds.), Flora da Serra do Cipó, Minas Gerais: caracterização e lista das espécies. Boletim de Botânica da Universidade de São Paulo 9(1).
Barros, F. 1991. Orchidaceae. Pp. 142-152. In: M.M.R.F. de Melo, F. de Barros, M.G.L. Wanderley, M. Kirizawa, S.L. Jung-Mendaçolli \& S.A.C. Chiea (Eds.), Flora fanerogâmica da Ilha do Cardoso: Caracterização geral da vegetação e listagem das espécies ocorrentes. vol. I. Instituto de Botânica, São Paulo.

Batista, J. A. N.; Bianchetti, L. B.; Salles, A. H.; Maury, C. M. R. F. \& Andrade, F. A. T. 1993. Espécies pouco conhecidas: Sarcoglottis heringeri Pabst. Orquidário 7(2): 52-58.

Bianchetti, L. B. \& Batista, J. A. N. 2000. Cyrtopodium latifolium (Orchidaceae): a new species from central Brazil. Lindleyana 15(4): 222-226.

Bianchetti, L. B.; Batista, J. A. N.; Salles, A. H.; Maury, C. M. R. F. \& Andrade, F. A. T. 1991. Contribuição ao conhecimento da família Orchidaceae no Distrito Federal - Novas citações. Pp. 384. In: Resumos do XLII Congresso Nacional de Botânica, Goiânia.

Castro-Neto, V. P. \& Campacci, M. A. 2000. Icones Orchidacearum Brasilienses I. Coordenadoria das Associações Orquidófilas do Brasil. 100tab.

Christenson, E. A. 1988. Nomenclatural changes in neotropical orchidaceae. Lindleyana 3(4): 221-223.

Christenson, E. A. 1996. Notes on neotropical Orchidaceae II. Lindleyana 11(1): 12-26.

Codeplan. 1984. Atlas do Distrito Federal II. Governo do Distrito Federal, Brasília.

Dressler, R. L. 1993. Phylogeny and classification of the orchid family. Dioscorides Press, Portland.

Filgueiras, T. S. \& Pereira, B. A. S. 1994. Flora do Distrito Federal. Orchidaceae. Pp. 391-393. In: M. N. Pinto (Org.), Cerrado: caracterização, ocupação e perspectivas. $2^{\circ}$ Edição. Ed. UnB/ SEMATEC, Brasília.

Garay, L. A. 1977. Systematics of the Physurinae (Orchidaceae) in the new world. Bradea 2(28): 191-204.

Garay, L. A. 1980. A generic revision of the Spiranthinae. Botanical Museum Leaflets, Harvard University 28(4): 277-425.

Hágsater, E. 1993. Epidendrum anceps or Epidendrum secundum ? Orquídea (Méx.) 13(1-2): 153-158.

Luer, C. A. 1978. Dryadella, a new genus in the Pleurothallidinae (Orchidaceae). Selbyana 2: 207-209.

Luer, C. A. 1982. A reevaluation of the genus Myoxanthus (Orchidaceae). Selbyana 7(1): 34-54.

Luer, C. A. 1986a. Icones Pleurothallidinarum I. Systematics of the Pleurothallidinae (Orchidaceae). Missouri Botanical Garden, St. Louis. 
Luer, C.A. 1986b. Icones Pleurothallidinarum III. Systematics of Pleurothallis (Orchidaceae). Missouri Botanical Garden, St. Louis.

Maury, C. M.; Ramos, A. E. \& Oliveira, P. E. 1994. Levantamento florístico da estação ecológica de Águas Emendadas. Boletim do Herbário Ezechias Paulo Heringer 1: 46-67.

Mendonça, R. C.; Felfili, J. M.; Walter, B. M. T.; Silva Junior, M. C.; Rezende, A. V.; Filgueiras, T. S. \& Nogueira, P. E. 1998. Flora vascular do cerrado. Pp. 289-556. In: S.M. Sano \& S.P. Almeida (Eds.), Cerrado: ambiente e flora. EMBRAPA-CPAC, Planaltina.

Menezes, L. C. 1990. Uma homenagem numa orquídea nova Encyclia lutzenbergerii L. C. Men. n.sp. Boletim CAOB 1: 4-8.

Menezes, L. C. 1991. Cyrtopodium aureum. Boletim CAOB 3(4): 50-52.

Menezes, L. C. 1992. Novas orquídeas em reservas militares. Boletim CAOB 4(1): 12-16.

Menezes, L. C. 1993. New taxa for the genus Cyrtopodium in Brazil. Schlechteriana 4: 146-151.

Menezes, L. C. 1995a. Novas orquídeas brasileiras. Boletim CAOB 5(1): 8-13.

Menezes, L. C. 1995b. In memory of Dr. J.A. Fowlie: Cyrtopodium fowliei. Orchid Digest 59: 17-18.

Menezes, L. C. 1996. Cyrtopodium withnerii L.C. Menezes sp. nov. Orchid Digest 60(1): 12-13.

Menezes, L. C. 1998. Sarcoglottis gonzalezii L.C. Menezes. Boletim CAOB 31: 27-28.

Miller, D.; Warren, R. \& Miller, I. M. 1994. Orchids of the high mountain Atlantic rain forest in southeastern Brazil. Salamandra, Rio de Janeiro.

Oliveira, R. S.; Batista, J. A. N.; Bianchetii, L. B. \& Proença, C. E. B. 1996 . Influência do fogo na floração de espécies de Orchidaceae em cerrado. Pp. 61-66. In: Anais do Simpósio Impacto das Queimadas sobre os Ecossistemas e Mudanças Globais. $3^{\circ}$ Congresso de Ecologia do Brasil, Brasília.

Pabst, G. F. J. 1964. Additamenta ad Orchidologiam Brasiliensem - V. Pp. 109-118. In: Anais do XV Congresso da Sociedade Botânica do Brasil, Porto Alegre.

Pabst, G. F. J. 1967a. Additamenta ad Orchidologiam Brasiliensem - VIII. Orquídea (R.J.) 29(1): 5-13.

Pabst, G. F. J. 1967b. Additamenta ad Orchidologiam Brasiliensem - IX. Orquídea (R.J.) 29(2): 62-66.

Pabst, G. F. J. 1971a. Orquídeas do cerrado. Pp. 161163. In: III Simpósio sobre o cerrado. E. Blücher, São Paulo.

Pabst, G. F. J. 1971b. New and Critical Orchids from Brazil. The Orchid Review 79: 53-55.
Pabst, G. F. J. \& Dungs, F. 1975. Orchidaceae Brasilienses, vol. 1. Brucke-Verlag Kurt Schmersow, Hildesheim.

Pabst, G. F. J. \& Dungs, F. 1977. Orchidaceae Brasilienses, vol. 2. Brucke-Verlag Kurt Schmersow, Hildesheim.

Pereira, B. A. S.; Mendonça, R. C.; Filgueiras, T. S.; Paula, J. E. \& Heringer, E. P. 1985. Levantamento florístico da área de proteção ambiental (APA) da Bacia do Rio São Bartolomeu, Distrito Federal. Pp. 419-492. In: Anais do XXXVI Congresso Brasileiro de Botânica, Curitiba.

Pereira, B. A. S.; Silva, M. A. \& Cunha-de-Mendonça, R. 1993. Orchidaceae. Pp. 35-36. In: Reserva Ecológica do IBGE, Brasília (DF): lista das plantas vasculares. IBGE, Rio de Janeiro.

Ribeiro, J. F. \& Walter, B. M. T. 1998. Fitofisionomias do bioma Cerrado. Pp. 89-166. In: S.M. Sano \& S.P. Almeida (Eds.), Cerrado: ambiente e flora. EMBRAPA-CPAC, Planaltina.

Romero, G. A. 1993. Notes on Pteroglossaspis (Orchidaceae), a new generic record for the flora of Colombia. Orquidea (Méx.) 13(1-2): 275-280.

Silva, M. F. F.; Silva, J. B. F.; Rocha, A. E. S.; Oliveira, F. P. M.; Gonçalves, L. S. B.; Silva, M. F. \& Queiroz, O. H. A. 1995. Inventário da família Orchidaceae na Amazônia brasileira. Parte I. Acta Botanica Brasilica 9(1): 163-175.

Szlachetko, D. L. \& Rutkowski, P. 1997. Two new species of the genus Sarcoglottis (Orchidaceae) from Brazil. Annales Botanici Fennici 34: 275-279.

Toscano-de-Brito, A. L. V. 1995. Orchidaceae. Pp. 725-767. In: B.L. Stannard (Ed.). Flora of the Pico das Almas: Chapada Diamantina - Bahia, Brazil. Royal Botanic Gardens, Kew.

Van den Berg, C. \& Chase, M. W. 2000. Nomenclatural notes on Laeliinae-I. Lindleyana 15(2): 115-119.

Van den Berg, C. \& Chase, M.W. 2001. Nomenclatural notes on Laeliinae-II. Additional combinations and notes. Lindleyana 16(2): 109-112.

UNESCO. 2000. Vegetação no Distrito Federal: tempo e espaço. Brasília.

Walter, B. M. T. \& Sampaio, A. B. 1998. A vegetação da fazenda Sucupira. Embrapa Recursos Genéticos e Biotecnologia, Brasília.

Warming, E. 1892. Lagoa Santa: Et Bidrag til den biologiske Plantegeografi. Bianco Los Kgl. HofBogtrykkeri, Kjøbenvavn.

Wood, J. J. 1989. Pteroglossaspis. Pp. 480-482. In: R.M. Polhill (Ed.). Flora of tropical East Africa. AA Balkema, Roterdam. 